\title{
Potential impact of phase change materials on energy reduction in Army buildings
}

\author{
Keith A. Rahn ${ }^{\text {, }}$ Kelli A. Polzin ${ }^{b}$ \\ ${ }^{a}$ Auburn University, 222 M. Miller Gorrie Center, Auburn, 36849, USA \\ ${ }^{b}$ Auburn University, 118 M. Miller Gorrie Center, Auburn, 36849, USA
}

\begin{abstract}
Buildings account for approximately $40 \%$ of energy consumption in the United States with Heating, Ventilation, and Air Conditioning (HVAC). The Army is the largest building owner within the Department of Defense and has the ability to impact the energy consumption within buildings reported in the United States. To date, Army has been making great strides in building new construction and renovation projects to meet high performance sustainable building goals set by the federal government and have further adopted ASHRAE 90.1 and 189.1 standards. With these additional goals of achieving Net Zero Energy, Energy Independence, and Energy Security to ensure continued support of the Army's Mission and maintaining National Security, there is a need to continue to drive further energy reduction within these buildings. Phase Change Materials have been identified as a building material that has potential to impact more energy reduction within our buildings by providing a lightweight thermal energy storage solution that stabilizes temperature swings within buildings. This material, when designed with consideration of local climate and building thermal loads, can support reduced HVAC system sizing needed to meet interior thermal comfort requirements thereby driving greater energy efficiency of buildings.
\end{abstract}

(C) 2018 The Authors. Published by Diamond Congress Ltd., Budapest University of Technology and Economics Peer-review under responsibility of the scientific committee of the Creative Construction Conference 2018.

Keywords: Army; Phase; Materials; Energy; HVAC;

\section{Introduction}

This research study evaluates the use and impact of phase change materials (PCM) on energy conservation and energy management in building applications for Army facilities. The research involves literature review, survey of professionals (manufacturers, vendors, construction contractors, and engineers) who are involved in the production, specification, or installation of PCMs in building envelopes, and analysis of collected data from buildings on Army installations where PCMs have been installed. The primary goal is to determine what PCMs may be appropriate and life cycle cost effective for Army building applications, including recommendations for installation locations within the building envelope, and appropriate Army facility types and climate zones in the United States. This research is significant as buildings consume approximately $40 \%$ of energy used in the world and contribute greatly to greenhouse gas emissions influencing greater changes in the climate. The Army, as the largest owner of building square footage in the Department of Defense, can make a significant impact in the United States' energy consumption through improved energy efficiency of its buildings.

Corresponding author: Keith A. Rahn email: kar0023@auburn.edu 


\section{Literature review}

According to the U.S. Energy Information Administration, as of 2015 residential and commercial buildings in the United States are consuming $40 \%$ of the nation's total energy used [8]. Estimates today project the energy consumption and associated greenhouse gas emissions from buildings will grow an additional 1.8\% per year through 2050 [1]. As an industry it is of paramount importance to identify life cycle cost effective and environmentally responsible technologies that can be integrated into new and existing buildings to decrease overall energy use. With a greater focus on interior thermal comfort of occupants and additional heat loads generated by lighting and plug loads in buildings HVAC systems are sized larger and account for a greater percentage of energy consumption within buildings to keep up. The use of PCMs as a passive system integrated into the building structure for minimizing temperature swings inside the building is potentially a life cycle cost effective solution that will allow for reduced HVAC system sizing and their associated energy consumption while meeting the same thermal comfort performance required by owners.

PCMs have been researched for decades in a variety of applications in building systems to reduce energy use through thermal energy storage capability. "PCMs utilize the principle of latent heat thermal storage (LHTS) to absorb energy in large quantities when there is a surplus and releasing it when there is a deficit" [19]. PCMs as thermal storage of latent heat inherently have the ability to store and release large amounts of energy in the process of melting and solidifying (liquid to solid, solid to liquid, etc.) in the process of changing physical states [12]. When the temperature rises during the day the material's chemical bonds will break apart at which point the material's solid state will transition to a liquid state, absorbing heat in this process. This is considered an endothermic process of phase change when heat is absorbed and the material changes to a liquid from solid [19]. As the temperature lowers - typically during the night, the PCM will expel heat previously absorbed and the material will transition back into a solid state, this is referred to as an exothermic process [22]. The phase change cycling PCMs go through as temperatures fluctuate aids in stabilizing indoor temperatures by minimizing swings [2].

\section{Types of phase change materials}

PCMs for building applications are typically maintained in solid-liquid states and fall into three categories of material types (Figure 1): Organic, Inorganic, and Eutectic. The categories of PCMs are divided further based on the component or compound makeup of the material as shown below in Figure 1. Comprehensive reviews of PCMs have been conducted recently with phase transition temperatures documented by these three categories [7]. Some researchers like Kylili and Fokaides [12] have chosen to categorized the eutectic type PCMs under the respective organic and inorganic categories rather than viewing them as a separate mixture type PCM category.

Of the variety of PCMs available across desired temperature ranges, the most prevalently used PCMs in construction applications have been paraffin waxes, fatty acids, salt hydrates, and eutectic organic/inorganic compounds in the past 30 years. When specifying PCMs for use in buildings envelopes it is necessary to understand the relationship of the PCM temperature and the melting enthalpy (kJ/l) [22]. In 1981, Schröder and Gawron [21] provided a summary of desirable properties required for PCMs to be utilized in buildings. Of particular note, these properties included matching of phase change temperature to the application with regards to climate, location in building and type of system, material stability, and fire safety. 


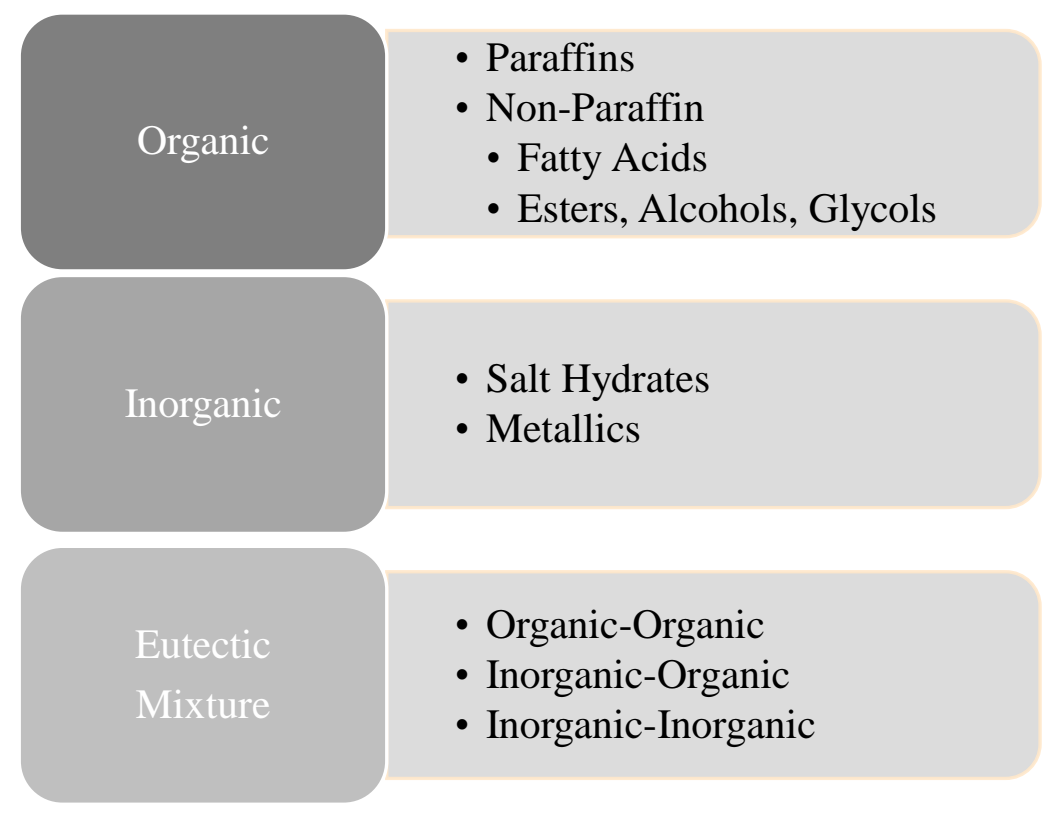

Fig. 1. Categories of phase change materials

\section{Building envelopes}

Encapsulation of PCMs for building envelope application is generally required for long term use of PCMs to prevent leaking associated with phase transition in these materials [17]. The encapsulating material used should not deteriorate over time or react with the PCM and should account for thermal conductivity and volume changes. Micro- and macro encapsulated PCMs appear to be the two main methods used for building applications. Macro encapsulation of PCMs refers to any type containerization of the material, above the micro- threshold and usually larger than $1 \mathrm{~cm}$ up to $7.5 \mathrm{~cm}$ [5], for incorporation into building materials or serving as an independent heat exchanger.

An advantage of microencapsulation type is greater heat exchange surface with the PCM leading to greater opportunity for heat transfer, although lower latent heat storage capacity per unit volume is experienced due to increased encapsulation material. The size of microencapsulated PCMs is small enough that they can be distributed in powder or liquid form added to other construction materials like concrete and gypsum board. This method of encapsulation is considered the most favorable method for integration into building materials [9].

The macro encapsulated containment methods for PCMs are typically flat, tubes, or spheres. A disadvantage of the size of macro encapsulated PCMs has to do with their low thermal conductivity and predisposition to transition phases at the edges first leading to slow energy uptake. This has the potential to cause the system to not discharge overnight completely [9]. Another disadvantage that increases the cost for this type of encapsulation has to do with the required durability of the container material against damage to prevent leakage [20].

As a passive system PCMs applied to building envelopes can influence thermal comfort of interior spaces contributing to reduction of building consumption by HVAC systems [3]. PCMs have been incorporated by manufacturers in a variety of building material applications including: PCM embedded gypsum wallboards, concrete, tiles, mats, windows, coatings and pellets integrated into cellulose insulation. Use of windows incorporating PCMs have been limited due to obstruction of views and translucent appearance. Although window views are desirable, so is daylighting of spaces and Li and Zheng [14] found double glazed windows with PCMs compared to the same windows without PCMs had a 30\% lower heat loss and 50\% lower solar heat gain. Mat PCMs have been applied as layers in the building envelope typically at the walls and roof.

Walls are found to be the most common portion of the building envelope where PCMs have been incorporated to date with PCM embedded wallboards making this a more favorable approach selected for integration in building 
envelopes. In much of the literature, it is recommended that wallboards are installed on the interior side of the building envelope due to the greater potential for absorbing and releasing heat to the space [22]. A variety of studies were conducted related to wallboard installation [10,12,11,4,18,15]. Additionally, macro encapsulated BioPCM product has been selected for application on interior side of building envelope directly behind standard gypsum wall board in renovations [16].

Concrete enhanced by PCMs has been referred to as thermocrete for being a heat storage medium utilizing an appropriate amount of PCM balanced with either a concrete mix or open-cell cement creating a low-cost storage material that retains structural and thermostatic properties [2]. Microencapsulated PCMs in walls and roofs has been investigated as a coating material on concrete and hollow bricks finding $30 \%$ reduction in indoor temperature swings possible in Algerian Climates [6].

Wahid et al. [25] studied paraffin wax based latent heat storage PCMs installed in walls, ceiling and floors identifying significant reduction in temperature fluctuation in the Middle East by storing solar energy for passive solar heating during the daytime hours. Additionally, shape-stabilized PCMs have been studied in floor applications finding rooms with PCM flooring to have a $3-4^{\circ} \mathrm{F}$ higher temperature than rooms without and a more stabilized temperature range for the room [26]. While in a study of single family homes in San Diego (climate zone 3) and Los Angeles (climate zone 9) integrating microencapsulated PCMs into concrete building envelope materials it was determined greater energy and cost savings could be achieved when applied to south and west walls and PCM temperature matched the desired interior temperature [24]. Biswas \& Abhari [4] studied fatty acid/glycerides suspended in HDPE pellets mixed with cellulose in exterior wall insulation practices as well as performed numerical modeling to correspond.

Few energy modeling programs have the ability to simulate accurate level of predictive behavior of PCMs and it may prove challenging for designers to attempt to take advantage of full energy savings and life cycle cost effective integrated design to right size HVAC equipment for true reductions anticipated from thermal control of the envelope with PCMs. PCMs were modeled using EnergyPlus in one study although it is noted that careful analysis should be completed as the accuracy of modeling programs have not been fully validated [23].

Contrary to Gao et al. [7] implication that PCMs are less effective and not recommended in humid and cold climates, Lei, Yang, and Yang [13] studied building envelope installed PCMs in Singapore, a tropical climate, with results of highly effective performance year round. The success was found to be attributed to the placement of PCMs on the exterior side of the building envelope having better results as well as PCMs with a temperature suitable for the application. This discrepancy between sources would indicate there is still research necessary in defining effective applications by climate zone with preferred PCM types and building envelope applications by location.

Kenisarin and Mahkamov [10] proposed additional research areas needed on the 'optimization of construction elements to provide maximum energy efficiency of building integrated PCM heat storage' and 'monitoring and recording of total energy consumed in both the reference and test rooms with PCM heat storage elements over a long period of experiments in order to carry out accurate assessment of the economic viability of application of passive thermal storage system.'

PCMs available in the building industry are diverse with a variety of characteristics to consider in the selection of PCMs for individual building application based on factors of climate zone and weather data, thermal conductivity, and desired interior thermal comfort range. Advantages and disadvantages appear to exist with each category of PCM available and these factors need to be weighed in determining appropriate integration with design of a building and its active systems. Life cycle cost effectiveness of PCMs has not been looked at in detail related to data collected in research as it relates to overall building energy use reduction impact on active systems.

\section{Methodology}

The qualitative research will implements a questionnaire survey of manufacturers, vendors, and engineers with expertise in phase change materials. This type of qualitative method of research allows for confirmation of personal perceptions and expert knowledge shared in the questionnaire survey of professionals working in the field of PCMs applied to building envelopes. There are multiple interrelated variables involved in this subject (weather data, climate zones, building space utilization, thermal comfort, size/type of HVAC equipment, etc.) found during the literature review process. The qualitative questionnaire survey approach mixed with a quantitative approach to analyze case 
study data will allow for more flexibility in identifying the impact these variables have on the effectiveness of PCMs beyond the limited Army case study sites available.

\subsection{Qualitative research}

Companies representing manufacturers, vendors, contractors, and engineers that are experienced in the field of PCMs installed in building envelopes either by the production and sale of such materials, or the design and installation of these materials were identified to participate in the survey. As this is an emerging technology in the field of construction that has not been widely used or is widely understood in the Architecture-Engineering-Construction (AEC) industry the pool of qualified potential survey participants in the United States was limited. Surveying a variety of professionals working in this field was selected due to the low number of manufacturers in this field and also to obtain different perspectives on PCM products from all knowledgeable parties involved in successfully integrating these products into buildings throughout the United States in a variety climate zones, as well as, knowledge from some more experienced manufacturers in Europe.

Twenty-one companies representing manufacturers, vendors, and engineers were identified as experienced in the field of PCMs installed in building envelopes on construction projects and were selected for participation in the questionnaire survey. Of the companies requested to respond twelve were identified as PCM manufacturers, six were PCM vendors, and three were engineers who had experience designing for and specifying PCMs in building envelopes.

\subsection{Quantitative research}

The quantitative research will document two existing case studies of projects on Army installations where phase change materials have been installed in building envelopes. Gas and/or electric utility usage data will be collected from these building sites for conducting analysis of archival data to evaluate the theory of optimized PCM placement in the building envelope for greatest potential effect on thermal comfort of building occupants and energy conservation potential in different climate zones.

Prior to the start of this research study, PCMs had been installed at least one year prior in Army facilities at two known installations located on Sierra Army Depot (Climate Zone: 5B) and Fort Irwin (Climate Zone: 3B). The two locations where PCMs were installed included existing buildings that underwent some level of renovation with goals for improvement in energy performance for the following building types at the respective locations: warehouse and a mix of barracks and offices. All locations had utility meter data available or utilized to conduct some level of performance verification of the building envelope renovation projects prior to the start of this study. Case study projects were selected as a part of this research study to evaluate current performance of buildings after the installation of PCMs in typical Army facility types at installations.

Both projects installed a BioPCM macro encapsulated product on the interior face of the selected insulation added to the building envelope as an energy conservation measure. Army building types represented where PCM was applied and measured include warehouse, administrative office space, and barracks, three common facility types for the Army. Both case studies provided some level of measurement and verification of the energy conservation measures. Methods were similar in that they both included temperature data loggers throughout the buildings and utility consumption rates were monitored to identify realized cost savings during the measurement and verification period to develop final results.

\section{Results}

Repeated themes were identified in the survey responses around general lack of knowledge related to how PCMs are designed, detailed, and specified as well as installed with some examples given about poor installation by early adopters and underestimated need for credible designs. Lack of knowledge, interest in changing, and forward thinking appears to be the main detractor from using PCMs in buildings with more knowledge needed by engineers, construction contractors, and owners. A second theme that emerged was cost and payback period associated with PCMs in the past with some claims that the costs are coming down on bio-based PCM products making them more attractive. Overall life cycle cost effective determination will be dependent on the success in overall design to achieve a lower total ownership cost based on economies achieved in reduced HVAC system size, reduced interior space, peak load shifting potential, energy use reduction and greater thermal comfort. Additional limitations identified by participants were 
history of PCMs including petroleum based PCMs that were widely used internationally in past decades, but not in the United States because of fire retardant laws restricting their use. Additionally, salt hydrate type PCMs were discussed as having a short life and marginal efficacy whereas bio-based PCMs are the first commercially available product for building envelopes that are becoming cost effective solutions for buildings in the United States.

Fort Irwin case study used an industry standard approach International Performance Measurement \& Verification Protocol Option B to execute the Measurement \& Verification (M\&V) study which included collection of weather data and additional data points for normalizing the results with the current ambient conditions and results were documented for a full year. The Sierra Army Depot case study only executed measurement and verification for a four-month period, however they took a different approach and compared data between the upgraded warehouse facility and the adjacent warehouse control facility without baseline measurements available like the Fort Irwin case study. Utility meter data was available for both, although the Fort Irwin case study did not have access to the gas meter data for heating periods and had to interpolate the use based on supply and return temperatures measured. Both case studies provided quantified results as a part of the M\&V period, however the Sierra Army Depot case study did not include a full year cycle of data to determine performance outcome for all seasons as seen in the Fort Irwin case.

Sierra Army Depot case study data was limited although realized between 33\% and 56\% reduction in gas utilities during the measured period over the adjacent warehouse control facility during the four-month period. Fort Irwin case study concluded the barracks achieved a $31.6 \%$ and the admin building achieved $39.1 \%$ energy savings associated with air conditioning over the baseline. The Fort Irwin case study did note times where the air conditioning was left running in the barracks although empty, this could account for the lower energy savings rate than the admin building. Natural gas energy savings during the heating period at Fort Irwin was estimated around 25\% on the admin building and 33\% on the barracks.

\section{Discussion}

The most significant impact generated by this study was evaluation of the thermal load generation expected within the structure based on building use to identify ideal locations to include PCM. Army building type recommendations based on high thermal load generation include industrial spaces, child daycare centers, clinics, schools, and offices which emerged from literature review and input from participants.

Climate and weather conditions of the project site should be evaluated to understand extent of passive PCM recharge is possible overnight. Preference indicated by participants in the research was given to Hot-Dry and Mixed-Dry climate zones. It is assumed additional active system intervention would be needed outside of these climate zones considered more ideal for application. It was noted in the research, if large diurnal temperatures are not present to support natural recharge, then assistance by active systems ventilation will need to be considered and designed appropriately to support transition of the PCM.

Integration of HVAC systems for recharging PCMs should include active monitoring and controls with temperature sensors at the PCM locations to trigger ventilation recharging of PCMs when needed. Ideally, for purposes of economizing the design solution and energy savings, the HVAC systems would be reduced in size based on the stabilizing temperature properties and peak load shifting of the PCM.

PCM Manufacturer and Mechanical System Designer should work together to select appropriate melting point and thermal storage capacity of the PCM for the project given the first two considerations above to inform active system design needed. Selection of PCMs should consider proven performance life expectancies given the projected building life. Flammability of paraffin and petroleum based PCMs that are popular and widely used overseas due to high effectiveness should be avoided for United States and Army facility construction as a matter of life safety and compliance with applicable fire codes.

When determining life cycle cost effectiveness of using PCMs, energy cost savings should not be the only factor to justify their use. Total ownership cost reduction must be quantified to include: reduced HVAC system size and cost; associated saved building materials and square footage for smaller mechanical space needed; peak load shifting capability to reduce demand charging by utility providers (if present); thermal comfort and associated energy savings due to temperature stabilization. 


\section{References}

[1] Akeiber, H., Nejat, P., Majid, M. Z. A., Wahid, M. A., Jomehzadeh, F., Zeynali Famileh, I., et al. (2016). A review on phase change material (PCM) for sustainable passive cooling in building envelopes. Renewable and Sustainable Energy Reviews, 60, 1470-1497. http://doi.org/10.1016/j.rser.2016.03.036

[2] Baetens, R., Jelle, B. P., \& Gustavsen, A. (2010). Phase change materials for building applications: A state-of-the-art review. Energy and Buildings, 42(9), 1361-1368. http://doi.org/10.1016/j.enbuild.2010.03.026

[3] Barzin, R., Chen, J. J. J., Young, B. R., \& Farid, M. M. (2015). Application of PCM energy storage in combination with night ventilation for space cooling. Applied Energy, 158, 412-421. http://doi.org/10.1016/j.apenergy.2015.08.088

[4] Biswas, K., \& Abhari, R. (2014). Low-cost phase change material as an energy storage medium in building envelopes: Experimental and numerical analyses. Energy Conversion and Management, 88, 1020-1031. http://doi.org/10.1016/j.enconman.2014.09.003

[5] Cabeza, L. F., Castell, A., Barreneche, C., de Gracia, A., \& Fernández, A. I. (2011). Materials used as PCM in thermal energy storage in buildings: A review. Renewable and Sustainable Energy Reviews, 15(3), 1675-1695. http://doi.org/10.1016/j.rser.2010.11.018

[6] Experimental Study on the Use of Microencapsulated Phase Change Material in Walls and Roofs for Energy Savings: Journal of Energy Engineering:(ASCE).(n.d.).RetrievedAugust14,2016,from about:reader?url=http\%3A\%2F\%2Fascelibrary.org.spot.lib.auburn.edu\%2Fdoi\%2Fabs\%2F10.1061\%2F\%2528ASCE\%2529EY.19437897.0000238

[7] Gao, E. J., Patel, J., Boddu, V. M., Stephenson, L. D., Lawrence, D., \& Kumar, Ashok. (2015). Simulated Aging and Characterization of Phase Change Materials for Thermal Management of Building Envelopes.

[8] How much energy is consumed in residential and commercial buildings in the United States? - FAQ - U.S. Energy Information Administration (EIA). (n.d.). Retrieved September 11, 2016, from http://www.eia.gov/tools/faqs/faq.cfm?id=86\&t=1

[9] Kalnaes, S., \& Jelle, B. (2015). Phase change materials and products for building applications: A state-of-the-art review and future research opportunities.

[10] Kenisarin, M., \& Mahkamov, K. (2016). Passive thermal control in residential buildings using phase change materials. Renewable and Sustainable Energy Reviews, 55, 371-398. http://doi.org/10.1016/j.rser.2015.10.128

[11] Kuznik, F., Virgone, J., \& Roux, J.J., (2009). Experimental assessment of a phase change materials integrated in building walls.

[12] Kylili, A., \& Fokaides, P. A. (2016). Life Cycle Assessment (LCA) of Phase Change Materials (PCMs) for building applications: A review. Journal of Building Engineering, 6, 133-143. http://doi.org/10.1016/j.jobe.2016.02.008

[13] Lei, J., Yang, J., \& Yang, E.-H. (2016). Energy performance of building envelopes integrated with phase change materials for cooling load reduction in tropical Singapore. Applied Energy, 162, 207-217. http://doi.org/10.1016/j.apenergy.2015.10.031

[14] Li, G., \& Zheng, X. (2016). Thermal energy storage system integration forms for a sustainable future. Renewable and Sustainable Energy Reviews, 62, 736-757. http://doi.org/10.1016/j.rser.2016.04.076

[15] Navarro, L., de Gracia, A., Niall, D., Castell, A., Browne, M., McCormack, S. J., et al. (2016). Thermal energy storage in building integrated thermal systems: A review. Part 2. Integration as passive system. Renewable Energy, 85, 1334-1356. http://doi.org/10.1016/j.renene.2015.06.064

[16] Nghana, B., \& Tariku, F. (2016). Phase change material's (PCM) impacts on the energy performance and thermal comfort of buildings in a mild climate. Building and Environment, 99, 221-238. http://doi.org/10.1016/j.buildenv.2016.01.023

[17] Ozonur, Y., Mazman, M., Paksoy, H.O., \& Evliya, H. Microencapsulation of coco fatty acid mixtures for thermal energy storage with phase change material. 741-749.

[18] Parameshwaran, R., Kalaiselvam, S., Harikrishnan, S., \& Elayaperumal, A. (2012). Sustainable thermal energy storage technologies for buildings: A review. Renewable and Sustainable Energy Reviews, 16(5), 2394-2433. http://doi.org/10.1016/j.rser.2012.01.058

[19] Phase change materials and products for building applications: A state-of-the-art review and future research opportunities. (n.d.). Retrieved August 29, 2016, from http://www.sciencedirect.com.spot.lib.auburn.edu/science/article/pii/S0378778815001188

[20] Schossig, P., Henning, H.-M., Gschwander, S., \& Haussmann, T. (2005). Microencapsulated phase-change materials integrated into construction materials

[21] Schröder, J., \& Gawron, K. (1981). Latent Heat Storage, Energy Res. 5. 103-109.

[22] Souayfane, F., Fardoun, F., \& Biwole, P.-H. (2016). Phase change materials (PCM) for cooling applications in buildings: A review. Energy and Buildings, 129, 396-431. http://doi.org/10.1016/j.enbuild.2016.04.006

[23] Tabares-Velasco, P. C., Christensen, C., \& Bianchi, M. (2012). Verification and validation of EnergyPlus phase change material model for opaque wall assemblies. Building and Environment, 54, 186-196. http://doi.org/10.1016/j.buildenv.2012.02.019

[24] Thiele, A. M., Jamet, A., Sant, G., \& Pilon, L. (2015). Annual energy analysis of concrete containing phase change materials for building envelopes. Energy Conversion and Management, 103, 374-386. http://doi.org/10.1016/j.enconman.2015.06.068

[25] Wahid, M. A., Hosseini, S. E., Hussen, H. M., Akeiber, H. J., Saud, S. N., \& Mohammed, A. T. (2016). An Overview of Phase Change Materials for Construction Architecture Thermal Management in Hot and Dry Climate Region.

[26] Zhang, Y., Xu, X., Di, H., Lin, K., \& Yang, R. (2006). Experimental Study on the Thermal Performance of the Shape-Stabilized Phase Change Floor Used in Passive Solar Buildings. 